46 (2) | 2017

Varia

\title{
La mentira toba de Monsieur Thouar
}

Le mensonge toba de Monsieur Thouar

The Toba lie of Monsieur Thouar

\section{Isabelle Combès}

\section{CpenEdition}

Journals

Edición electrónica

URL: https://journals.openedition.org/bifea/8463

DOI: 10.4000/bifea.8463

ISSN: 2076-5827

\section{Editor}

Institut Français d'Études Andines

\section{Edición impresa}

Fecha de publicación: 1 agosto 2017

Paginación: 331-351

ISSN: 0303-7495

\section{Referencia electrónica}

Isabelle Combès, «La mentira toba de Monsieur Thouar», Bulletin de l'Institut français d'études andines [En línea], 46 (2) | 2017, Publicado el 08 août 2017, consultado el 28 juin 2022. URL: http:// journals.openedition.org/bifea/8463 ; DOI: https://doi.org/10.4000/bifea.8463

Les contenus du Bulletin de l'Institut français d'études andines sont mis à disposition selon les termes de la licence Creative Commons Attribution - Pas d'Utilisation Commerciale - Pas de Modification 4.0 International. 


\title{
La mentira toba de Monsieur Thouar
}

\author{
Isabelle Combès*
}

\section{Resumen}

Jefe de una expedición exploradora al Chaco boliviano en 1887, el francés Arthur Thouar atribuyó su fracaso a la falta de agua, a la mala voluntad de los colonos criollos, a los errores geográficos de sus predecesores y, sobre todo, a los indígenas tobas del Pilcomayo y a los padres franciscanos. Alteró y modificó sus informes en consecuencia, tanto para justificarse como para presentarse como el glorioso sucesor de Jules Crévaux. Su principal herramienta en este sentido fue la manipulación y la invención de la historia de Yalla, una joven toba.

Palabras clave: exploraciones al Chaco boreal, relatos de viaje, Arthur Thouar, Doroteo Giannecchini, Jules Crévaux

\section{Le mensonge toba de Monsieur Thouar}

\section{Résumé}

Chef d'une expédition d'exploration au Chaco bolivien en 1887, le Français Arthur Thouar a attribué son échec au manque d'eau, à la mauvaise volonté des colons créoles, aux erreurs géographiques de ses prédécesseurs et, surtout, aux Indiens Toba du Pilcomayo et aux Pères Franciscains. Il a altéré et modifié ses rapports en conséquence, pour se justifier et se présenter comme le glorieux successeur de Jules Crévaux. Son principal outil dans cette tâche a été la manipulation et l'invention de l'histoire de Yalla, une jeune Toba.

Mots-clés : explorations au Chaco boréal, récits de voyage, Arthur Thouar, Doroteo Giannecchini, Jules Crévaux 


\title{
The Toba lie of Monsieur Thouar
}

\begin{abstract}
Leader of an expedition of exploration to the Bolivian Chaco in 1887, the Frenchman Arthur Thouar attributed his failure to lack of water, the geographical errors of his predecessors, the ill-will of the créole population and mostly to the Franciscan missionaries and the Toba indians of the Pilcomayo river. Thouar altered his reports to justify his actions and to present himself as the glorious heir of explorer Jules Crévaux. His main tool to achieve this was his manipulation and invention of the story of Yalla, an indigenous Toba woman.
\end{abstract}

Keywords: Explorations of the Northern Chaco, travelogues, Arthur Thouar, Doroteo Giannecchini, Jules Crévaux

Al inicio de la década de 1880 Bolivia ya ha virtualmente perdido su litoral en la Guerra del Pacífico que la opuso a Chile. Para salir del enclaustramiento, las esperanzas se vuelcan hacia el Atlántico y los ríos que permitirían alcanzar el océano por la cuenca amazónica o la cuenca platense. En este contexto se reanudan con más ímpetu las exploraciones al Chaco boliviano, que habían empezado a mediados de siglo bajo el gobierno de José Ballivián (Groff Greevers, 1987; García Jordán, 2001).

En 1882, el médico de la marina francesa Jules Crévaux, afamado explorador de la Amazonía, emprende la bajada del río Pilcomayo, con el objetivo de alcanzar el Paraguay. Su expedición acaba siendo masacrada por los indígenas entre Teyu y Cabayurepoti. En 1883 parte una expedición boliviana al mando de Daniel Campos, acompañada por el explorador francés Arthur Thouar, encargado por Francia de investigar la muerte de Crévaux y buscar posibles sobrevivientes. La columna funda en Teyu la Colonia Crévaux y llega en noviembre a Asunción del Paraguay.

En diciembre de 1886, finalmente parte otra expedición, esta vez al mando de Thouar. Su objetivo es llegar hasta Puerto Pacheco, puesto boliviano fundado en 1885 en el Alto Paraguay por Miguel Suárez Arana1. Se trata de la actual Bahía Negra que pertenece hoy a Paraguay. La expedición Thouar debía partir desde el Isoso sobre el río Parapetí, alcanzar las salinas de Chiquitos y, de ahí, abrir un camino hasta Puerto Pacheco. Habiendo fracasado en el Isoso, Thouar busca mejor suerte al sur y se dirige a Macharetí, para luego bajar el río Pilcomayo. Diez meses después vuelven los expedicionarios agotados, desalentados, frustrados y resentidos, sin haber conseguido nada.

Tal vez por su mismo fracaso, esta expedición dio origen a una considerable y variada masa de documentos: libros, informes, cartas, folletos, boletines, mapas,

1 Explorador y empresario, Miguel Suárez Arana fue el fundador de la Empresa Nacional, sociedad de colonización del oriente boliviano, y de la ciudad de Puerto Suárez (1875) (Barnadas dir., 2002, t. 2: 946). 
croquis, incluso algunos cuentos de ficción productos de las veleidades literarias del dibujante francés de la exploración, Théophile Novis (Novis, c. 1890). Estos cuentos se inspiran de los pormenores del fatigoso viaje y de personajes reales encontrados en el Chaco. Entre ellos figura Yala, muchacha mataca en la ficción, inspirada por una histórica joven toba cuya historia puede leerse en los escritos del franciscano Doroteo Giannecchini, capellán de la expedición de 1887 y, sobre todo, en los del propio Thouar. Aunque, y este es el tema de estas páginas, el cuento no siempre es el que se cree.

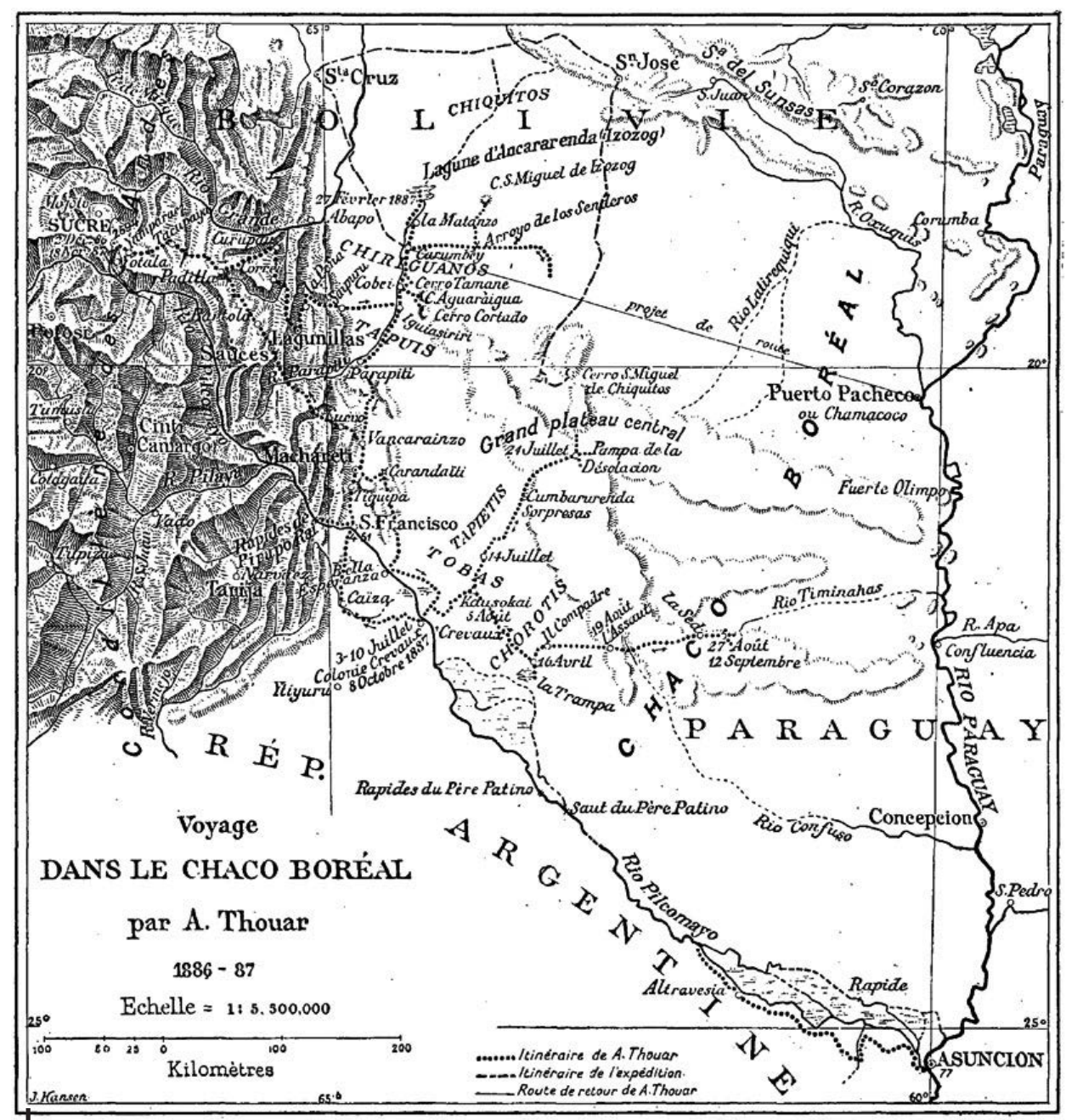

Figura 1 - Mapa del recorrido de la misión Thouar

Sacado de Thouar, 1889: 203 


\section{YALLÁ EMBAJADORA}

Yalla (o Yallá, Yala) aparece por primera vez en la historia bajo la pluma de Giannecchini. Estamos a inicios de 1882 en Tarija y Crévaux está preparando su expedición al río Pilcomayo. Encargado de auxiliarle en todo lo necesario gracias a su gran conocimiento de los indígenas chaqueños, Giannecchini comienza «a arbitrar medios para el efecto»:

Sabía yo que de algunos meses acá, una hija de un cacique toba de mucho prestigio entre sus connacionales, se hallaba al servicio de una respetable señora tarijeña. Emití, pues, la idea de que se le diera la libertad y se la despachase a su tierra como mensajera de paz (Giannecchini, 2006 [1882]: 632).

Todos encuentran la idea excelente, menos la dueña de la toba que reclama una compensación por perder a su sirvienta.

La Prefectura no sólo pagó lo que pretendía la señora, sino que regaló a la misma toba y le dio, además, varios regalos para llevar a sus deudos a fin que cumpliera con empeño la misión que se le confiara cerca de su nación (Giannecchini, 2006 [1882]: 632).

Es entonces cuando el prefecto de Tarija escribe al gobierno que «la india Petrona Signaí, hija de uno de los capitanes más influyentes de la raza choroti» y prisionera desde 1881 en Tarija, será enviada de vuelta al Chaco «en calidad de emisario» (Giannecchini, 2006 [1882]: 632-633). Debemos atribuir lo de «choroti» a un lapsus, pues en lo sucesivo Petrona aparece sin ambigüedad como toba.

Giannecchini y Petrona se reúnen el 24 de marzo con Crévaux en Ivitivi, antes de entrar al Chaco. El explorador francés, dice, «empezó a considerar a la india como a su hija y como a la principal cooperadora de su expedición» (2006 [1882]: 633). La iba a necesitar incluso más de lo pensado. En Ivitivi en efecto, cae la noticia: los colonos de Caiza, poblado criollo de la «frontera» del Chaco, han salido a una expedición punitiva contra los indios del Pilcomayo que robaron caballos. El 30 de marzo regresa «la ominosa expedición» con siete cautivos noctenes (matacos). Cinco de ellos, todavía niños, son llevados a la misión de San Francisco.

La vista de los cinco chiquillos y la relación del éxito de la expedición ime hicieron temblar por Mr. Crévaux! Le ratifiqué el pronóstico del mal éxito que tendría su exploración a causa de las muertes y cautivos; porque los parientes de ellos no dejarían de vengarse a su paso con él, pues así lo exigía su costumbre y su código (Giannecchini, 2006 [1882]: 637).

En estas circunstancias, «la toba Yallá (Petrona)» se convierte en «la única esperanza, aunque débil», para el éxito de la misión Crévaux (Giannechini, 2006 [1882]: 638). He aquí Petrona devenida Yallá — sin explicación sobre el cambio de nombre- y ratificada como toba. El 4 de abril Yallá sale hacia el Pilcomayo, colmada de recomendaciones y recados por parte de Giannecchini para los caciques indígenas, en especial para su padre, el cacique Caligagae. Esta es la primera mención del padre de Yallá; de él, sabemos que era hijo de un tal Icuru 
que se distinguió años atrás, en 1874, en diversos asaltos y robos a las misiones franciscanas de San Francisco y de San Antonio del Pilcomayo (Giannecchini, 1988 [1879]: 328-29; Anales, 2006 [1879-1905]: 1312).

Racional e inteligente como era, [Yallá] comprendió perfectamente su misión y prometió cumplirla [...] salió contenta y agradecida, prometiendo estar de vuelta con sus parientes entre unos 12 o 15 días.

El final es triste: «la Yallá no regresó al tiempo prefijado»y, el 27 de abril, Crévaux caía víctima de los indios en el paraje de Teyu, a orillas del Pilcomayo (Giannecchini, 2006 [1882]: 639-640).

Pero la historia no acaba ahí, como tampoco el papel de «la Yallá» y su parentela. De hecho, no todos los expedicionarios murieron en las playas del Pilcomayo. El francés Haurat y el guía toba argentino Chilata (alias Carmelo Blanco) cayeron prisioneros de los tobas, así como el joven boliviano Francisco Zeballos. Este fue rescatado después, gracias a la intervención de los padres franciscanos. Entrevistado por un periódico tarijeño, Francisco contó lo poco que sabía: logró huir en este funesto 27 de abril, pero

[...] lo alcanzó un toba y lo hirió con la lanza en una pierna; acudió otro y lo arrancó de las manos de su agresor y lo llevó a Cabayu-repoti y de allí a Teyu: de donde el padre de la toba Petrona, que Crévaux llevó de ésa, y un capitán toba, lo devolvieron al P. Vicente Marcelleti en la misión de San Francisco Solano, con el objeto de hacer las paces y obtener perdón de su nefando y horroroso asesinato2.

En esta ocasión Marcelleti logra hablar con tres tobas, incluyendo a Caligagae, el padre de Yallá. Él y sus colegas niegan enérgicamente su culpabilidad:

se defendieron con decir no haber tenido ellos parte en el asesinato, haber sido los del río muy abajo a causa de expediciones pasadas [...] que los tobas de río abajo achacaban a ellos el crimen, siendo así que eran inocentes (Marcelleti, carta del 10.VII.1882, en Giannecchini, 2006 [1882]: 647).

Es un hecho que los tobas de Teyu, donde fue matado Crévaux, estaban separados de los de río abajo «por el corto territorio ocupado de los chorotis», aunque mantenían relaciones con sus parientes abajeños (Corrado, 1884: 397). En todo caso, y aunque esto no logre eximirle de toda sospecha, el papel de Caligagae en la devolución de Zeballos puede coincidir con una versión que circulaba en ese entonces acerca de la suerte de los otros dos sobrevivientes:

Escaparon también de entre los mártires el timonero francés Haurat y un argentino Carmelo Blanco, quienes tomados prisioneros fueron salvados de pronto por la tierna y caritativa influencia de la india Yalla que los libró de la muerte. Ellos soportaron su cautiverio durante cinco meses al cabo de los cuales murieron, quizá también sacrificados (Paz Guillén, 1886: 11).

2 Este texto, publicado en La Estrella de Tarija el 22.VII.1882, fue reproducido por muchos autores, entre ellos Giannecchini (2006 [1882]: 656-657), Campos (1888: 631) y Storm (1892: 15). 
Sin proporcionar su nombre, Storm da pocos años después la misma versión de la historia: según él, Haurat y Chilata fueron «salvados de la muerta inmediata por la intervención de una india» (Storm, 1892: 14). Intervención poco eficaz al parecer, pues ambos «perecieron después de sufrimientos atroces, agarrotados en unos troncos de algarrobo y sirviendo de blanco a las flechas de los indios. Este suplicio duró más de seis meses» (Thouar, 1997 [1891]: 80).

\section{YALLA TRAIDORA}

La supuesta intervención de Yallá a favor de los prisioneros y la de su padre en el rescate de Francisco Zeballos dejan en suspenso el verdadero papel desempeñado por la joven toba en la masacre de la misión Crévaux. De hecho, Giannecchini solo dice que no volvió y no agrega más comentarios. Por el contrario, en la versión de Thouar la duda ya no es posible y Yalla (ahora sin acento, tal vez porque un francés es quien escribe) es una redomada traidora.

Arthur Thouar se encontraba en abril de 1882 en Santiago de Chile; el gobierno francés aprovechó su presencia para enviarlo a investigar sobre la masacre de la misión Crévaux. En 1883, Thouar se juntó en Tarija con la expedición dirigida por Daniel Campos, delegado del gobierno boliviano. Sobrepasando sus objetivos iniciales (que, de parte del gobierno boliviano, consistían más que todo en sentar presencia en el Chaco y fundar varias colonias), los expedicionarios llegaron hasta Asunción en noviembre de 1883. Además de numerosos informes y cartas, varios libros fueron escritos sobre esta expedición, entre ellos los de Campos (1888) y de Thouar, quien publicó en 1884 el relato de su viaje en la revista francesa Le Tour du Monde. La parte en la cual evoca los preparativos de la expedición Crévaux (y el papel de Yalla en ellos) retoma textualmente el libro de Giannecchini de 1882 (Thouar, 1884: 226-229). Sin embargo cuando, en 1891, Thouar reúne sus diversos relatos de viaje en un solo libro, altera su texto agregando a propósito de Yalla un comentario suelto y algunos párrafos.

El comentario se inserta cuando el padre Giannecchini presenta Yalla a Crévaux, explicándole que podrá servir como embajadora de paz. Thouar dice en 1891, y no así en 1884: «sólo después se supo que la joven había dejado contrariada la casa de Tarija donde servía» (Thouar, 1997 [1891]: 71). En cuanto a los párrafos agregados en 1891, se los apreciará mejor comparando los diferentes textos:

Giannecchini (2006 [1882]: 639-640)

[Dice Crévaux:] «iEh! Si me muero, me muero; si no se arriesga, estaremos siempre a oscuras».

La única esperanza que quedaba era el regreso de Yallá con sus padres y demás capitanes del este que habíamos mandado llamar, para saber lo que los tobas pensaban o dijesen relativamente al último asalto que les habían dado los caiceños. Mas, esta esperanza también se desvaneció porque la Yallá no regresó en el tiempo prefijado. 
Los tobas, ¿habrán creído a mis palabras de paz que la Yallá les llevó, cuando los hechos últimos hablaban muy alto en contrario?

El día 13 de abril llevé a Mr. Crevaux y al Sr. Delegado a reconocer el Pirapo...

2) Thouar (1884: 229)

iY si tengo que morir, dijo, moriré! ipero si no se arriesga nada, no se descubre nada y se estará siempre en las tinieblas!

Esperaba ver volver a la india Yalla con sus parientes y los capitanes indios, porque deseaba vehementemente saber lo que pensaban los tobas: pero su esperanza fue defraudada... ila Petrona no volvió en la época fijada!

El 13 de abril acompañado por el P. Doroteo y el delegado boliviano, fue a reconocer el salto del Pirapó...

3) Texto agregado por Thouar, aquí en negrita (1891: 38; 1997 [1891]: 7677)

iY si tengo que morir, dijo, moriré! ipero si no se arriesga nada, no se descubre nada y se estará siempre en las tinieblas!

La Petrona no volvió en la época fijada. El Dr. Crévaux no tomó en cuenta este hecho que debía haberlo puesto en guardia contra las promesas engañosas de los indios. Por otra parte el diálogo entre los tobas y la india no dejaba ninguna duda respeto a la premeditación del crimen y al rol funesto jugado por la india.

Unos gringos carayes (extranjeros cristianos), dijo ella, van a venir pronto por el Pilcomayo. Se dirigen al Paraguay. Después de ellos vendrán otros que ocuparán el río y ustedes ya no podrán pescar.

¿Cuántos son?, preguntaron los tobas.

La Yalla trazó en la arena unas pequeñas rayas, tantas como hombres habían en la misión, así les avisó que eran veintiuno.

¿Hay cuicos (soldados bolivianos)?

No.

\section{¿Tienen armas?}

iSí! Pero no saben servirse de ellas. iSon gringos muy sonsos!

El 13 de abril acompañado por el P. Doroteo y el delegado boliviano, fue a reconocer el salto del Pirapó...

En 1883 Thouar no conoció personalmente a Yalla. Sí lo hizo en 1887 durante su siguiente expedición. La primera hipótesis es entonces que los detalles de este diálogo le fueron comunicados por la misma toba -iquién más iba a conocerlos? - y que por eso los agregó en su edición de 1891.

Sea como fuere, el Thouar de 1891 parece mucho más convencido de la culpabilidad de Yalla que el que copió el texto de Giannecchini en 1884. Lo demás del texto de 1891 no contiene cambios significativos en relación con la 
primera publicación en Le Tour du Monde, aparte de la frase ya citada sobre el suplicio de Haurat y Chilata que no figuraba en 1884. Ni en 1884 ni en 1891, Thouar menciona el supuesto papel de salvadora de Yalla para con Haurat y Chilata, ni el de su padre en el rescate del joven Zeballos.

En ambos textos, hay que notarlo, el francés se presenta como un acérrimo defensor de los padres franciscanos (y de Giannecchini en particular), que fueron acusados por los colonos criollos de haber sido cómplices o incluso instigadores del asesinato de Crévaux. En efecto, y en el contexto de una fuerte rivalidad entre misioneros y colonos acerca del control de los indios y su mano de obra 3 , los criollos de Caiza y demás poblados de la frontera chaqueña acusaron formalmente a los padres de ser «causas mediatas de todo el fracaso. Los que esparcieron estas voces fueron los que con razón temían la responsabilidad del funesto suceso» (Giannecchini, 2006 [1882]: 644). Thouar no cree ni un segundo en la versión de los colonos y de hecho, en su texto sobre su malograda expedición en el delta del Pilcomayo en 1885, no se priva de fustigar a estos «desclasados, condenados, marginados [...] más temibles que los inofensivos indios» (Thouar, 1997 [1891]: 193) cuya expedición punitiva fue, en la versión franciscana, la causa directa de la venganza toba contra el inocente Crévaux. Al finalizar el relato de su viaje de 1883, Thouar escribe sin ambigüedades:

es para mí una gran satisfacción haber defendido de las más terribles sospechas a aquellos infelices misioneros italianos, cuya vida y seguridad se hallaban amenazadas (Thouar, 1997 [1891]: 163)4.

\section{YALLA SALVADORA}

La expedición de 1887 marca la reaparición de Thouar en el escenario boliviano y la de Yalla en el contexto pilcomayense. En Buenos Aires (adonde llega al finalizar su exploración en el delta del Pilcomayo por cuenta del gobierno argentino), Thouar recibe una invitación del gobierno boliviano para «volver a [sus] estudios» (Thouar, 1997 [1891]: 221), es decir concretamente encabezar una nueva expedición hacia el Paraguay, esta vez hacia Puerto Pacheco; según Daniel Dory (2005), Thouar fue en realidad enviado a Sucre por el Centro Boliviano de Buenos Aires y el gobierno aprovechó su presencia para encargarle la expedición.

Sea como fuere, los expedicionarios salen el 2 de diciembre de 1886 de Sucre, rumbo al Isoso. Nuestro ya conocido padre Giannecchini es el capellán designado de la exploración a la que alcanza en el Isoso. Según el mismo padre, Thouar le habría escrito el 10 de enero de 1887 desde Lagunillas, manifestándole su complacencia por tener a un padre franciscano a su lado «para vengar

3 Sobre este contexto durante la expedición Thouar, ver Roux, 1997 y Dory, 2005; análisis más detallados en el contexto de la colonización del Chaco en García Jordán, 2001 y Langer, 2009.

4 Cuando, como aquí, los textos de 1884 y 1891 coinciden, solo cito la traducción española para no sobrecargar las referencias. 
públicamente [...] las infames calumnias que pesaron sobre la congregación a la muerte de Crévaux» (Giannecchini, 1896: 16).

Las tentativas por abrir un camino desde el Isoso hasta las salinas de Chiquitos y de ahí a Puerto Pacheco fracasan todas y, en mayo, los expedicionarios abandonan el Parapetí por el Pilcomayo, dirigiéndose a la misión de Macharetí al sur, para de ahí partir río abajo. En este contexto es cuando reaparece Yalla en nuestra historia, y también cuando empiezan a aparecer graves problemas entre el explorador francés y su capellán italiano.

El 20 de mayo de 1887, desde Macharetí, Thouar decide pasar a la misión de San Francisco «para evaluar la disposición de los tobas» (1997 [1891]: 392). En efecto en esta misión, fundada en 1860, vivían familias tobas del Pilcomayo. Thouar cuenta su estadía en San Francisco:

Durante la visita a los ranchos de los tobas me encuentro con el indio Caligagae y su hija Yalla, quien tuviera un rol tan funesto en la masacre de la misión Crévaux. Al caer la noche tenía la intención de acercarme a ellos, pero la puerta de la misión estaba cerrada con llave. Esta precaución me extrañó. Hasta ahora yo siempre había gozado de una amplia libertad en la casa de los padres (Thouar, 1997 [1891]: 392).

Dándose modos para entrar Thouar, acompañado por el dibujante Novis, logra entrevistarse con la toba y hablarle, no de la expedición que está por empezar, sino de la que fue masacrada cinco años antes. Yalla, dice, «conserva mayores recuerdos» de Haurat. La joven termina dando al francés los nombres de los tobas que asesinaron a Crévaux: Cuserai, Cototo, Sugai, y otros más.

Esta entrevista no fue la última. Pronto me gané toda la confianza de la pobre india y gracias a ella supe todas las circunstancias de la masacre de la expedición. Las ingenuas manifestaciones de su amistad eran a veces bastante molestas: por ejemplo un día en un cuarto de la misión donde me hallaba con Novis muy entretenido en escribir, se entró sin decir nada y al ver que no terminaba de atenderla, me abrazó fuertemente tomándome por el cuello, después me soltó alisándose y peinándose los cabellos, buscaba en un espejo una actitud graciosa (Thouar, 1997 [1891]: 394).

Sin embargo, durante esta primera entrevista nocturna, la conversación se ve interrumpida un momento «por la llegada de dos chiriguanos, que según ella son espías enviados por el padre». De hecho, remata Thouar, al día siguiente el padre Giannecchini «parece muy molesto por mi visita» (1997 [1891]: 394).

El mismo Giannecchini, si bien señala la ida de Thouar a San Francisco, no menciona ni esta oportunidad ni tampoco la presencia de Yalla en otro momento de su Diario. Sin embargo es muy probable que sí haya estado presente. Novis esbozó en esta ocasión su retrato (fig. 2); la presencia de su padre está comprobada, pues participó pocos días después de una entrevista

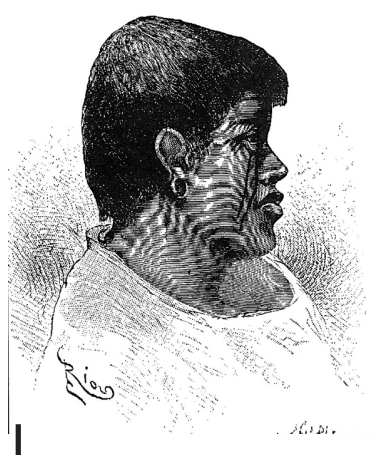

Figura 2 - Yalla

Dibujo de Riou, con base en un croquis de Novis; Thouar, 1889: 206 
celebrada en Macharetí entre Thouar y varios caciques indígenas para preparar la expedición. En esta ocasión, «Caligagai» afirmó que los indígenas estaban conformes y «que no se opondrían al paso de la columna»5. El mismo Caligagae había participado pocos años antes, en 1884, en la celebración de un tratado de paz con los blancos de la frontera chaqueña. En esta ocasión, el documento lo califica de «Capitán grande» del pueblo de Teyu (Tratado, 1988 [1884]).

Tal vez porque está enamorada del explorador francés — como podrían sugerirlo sus «ingenuas manifestaciones» de cariño-, a partir de este primer encuentro Yalla acompañará, como una sombra benéfica, las tribulaciones de Thouar en el Pilcomayo. Paralelamente, los padres franciscanos en general y Giannecchini en particular, aparecen bajo un perfil cada día más siniestro. Apenas dos páginas después de referir su entrevista con Yalla, Thouar dice haber recibido una carta de un francés no identificado, residente en la frontera chaqueña, que le recomienda prudencia: «la confianza del doctor [Crévaux] en los consejos de los padres ha sido la causa de su muerte». La misiva está «dirigida sobre todo contra el padre Doroteo», y este «se turba y su confusión no pasa desapercibida» cuando se entera (Thouar, 1997 [1891]: 396). Este es el momento escogido por Thouar para anunciar a sus lectores:

En las páginas precedentes me he limitado a relatar hechos de los cuales mis camaradas han sido héroes o testigos, en adelante y en cuanto a lo que se refiere más particularmente a la Misión Crévaux y al rol de los padres, citaré también los acontecimientos sin comentarios, tal como los he consignado y controlado de acuerdo a documentos (Thouar, 1997 [1891]: 397).

La turbación de Giannecchini debió ser mucha. En todo caso, a partir de este momento, y de la manera neutral e imparcial anunciada, Thouar parece estar lejos de pensar en «vengar públicamente» a los franciscanos, e inclinar la balanza a favor de las acusaciones vertidas por los criollos en 1882 en contra del padre Doroteo.

A lo largo del viaje que empieza Pilcomayo abajo, Yalla vuelve a aparecer en tres ocasiones para entrevistarse, siempre de noche y en gran secreto, con el explorador francés. El 7 de julio en la Colonia Crévaux, «uno de los indios chorotis [le] procura una entrevista con la Yalla» (que, entonces, debió haber seguido la tropa expedicionaria desde Macharetí, o haberla alcanzado en el camino). El encuentro tiene lugar «en las silenciosas orillas del Pilcomayo, idonde el murmullo silencioso de las aguas habíase llevado, cinco años atrás, los últimos gritos de las víctimas!». Yalla recomienda a su protegido cuidarse de los tobas que planean atacarlo río más abajo. De hecho el toba Cototo (denunciado por ella como asesino de Crévaux) solo participó de la reunión en Macharetí «para aconsejar a los indios que nos resistan», y así lo planeaban, «ante todo aquellos que estuvieron presentes, únicamente para reconocerme más tarde, en la entrevista de Macharetí». Pero Yalla promete vigilar a los pérfidos indios, e informar a Thouar (Thouar, 1997 [1891]: 407).

5 Carta de Thouar al ministro de Relaciones Exteriores, Macharetí, 3.VI.1887 (Ministerio de Relaciones Exteriores y Colonización, 1887: 9). 


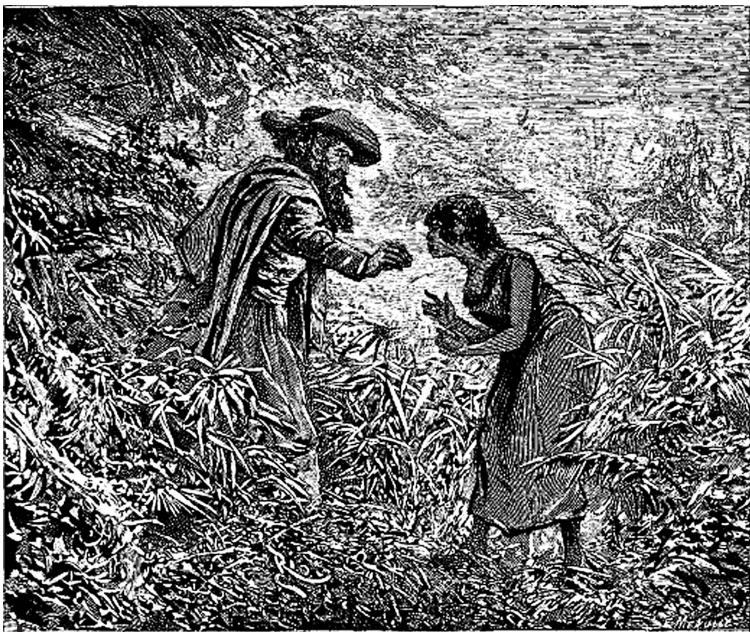

Figura 3 - Entrevista con Yalla

Dibujo de Riou con base en un croquis de Thouar (Thouar, 1890: 183)

Un mes después, el 10 de agosto, Thouar y un puñado de exploradores abandonan el grueso de la expedición y se internan Chaco adentro con la esperanza de alcanzar el Paraguay. Pero una nutrida tropa de indios, tobas en su mayoría, está al acecho y llega al campamento de los expedicionarios. Estos se asustan pero no así Thouar, pues «la presencia de la Yalla entre los visitantes [le] da cierta confianza» (Thouar, 1997 [1891]: 428). La joven parece haber seguido la expedición junto con los tobas entonces. Nueva entrevista nocturna y secreta. Las noticias son alarmantes. Los tobas, noctenes y tapietes «se han reunido a una jornada de marcha» y esperan a los expedicionarios para atacarlos. Aquellos que llegaron al campamento bajo pretexto de amistad están encargados de guiarlos traidoramente hacia el lugar del asalto. El ataque es inminente, y «ilos emisarios que llegaban de las misiones iban recorriendo sus tribus para excitarlas al combate!» (Thouar, 1997 [1891]: 430).

Siguen varios ataques indígenas, todos felizmente rechazados, hasta el 20 de agosto. Luego cesan repentinamente; el problema de los exploradores es más bien la cruel falta de agua que empieza a diezmar la pequeña tropa. El 29 de septiembre, nueva separación: Thouar, Novis y otros dos exploradores se quedan solos, decididos a «morir o llegar juntos» al soñado Paraguay. Siguen vigilados por los indios, atormentados por la sed, hambrientos, exhaustos. En estas terribles circunstancias, el 30 de septiembre al caer la noche, ligeros crujidos atraen la atención de Thouar: «es mi valiente toba» que reaparece, con el dedo en la boca intimándole silencio. «Me dice que los tobas nos rodean [...] van a llegarles refuerzos esta noche o mañana para atacarnos numerosos». Pero Yalla trae también una luz de esperanza en esta desesperada situación: «ella sabe que el buruhicha (grande), así llamaba al comandante de las colonias, coronel Martínez, viene a socorrernos» (Thouar, 1997 [1891]: 465).

El coronel llega, efectivamente, el 1을 de octubre, precisamente en el momento en que van a atacar los indios. Si bien, según Giannecchini, Martínez se enteró de la posición de los expedicionarios gracias a un indio choroti, según Thouar fue «la Yalla, mi pobre toba, con firme asiduidad y vigilancia sin falla», quien «empujó a este choroti a proponerse como guía» (Thouar, 1997 [1891]: 468). Y esta es la última mención de Yalla en el relato de Thouar. 


\section{HISTORIA DE UN FRACASO}

La expedición de 1887 fue un rotundo fracaso, que Giannecchini atribuye sin vacilar «a las órdenes y dirección de su Jefe Superior Mr. A. Thouar» (Giannecchini, 1896: 133). Bien podría dudarse de las aseveraciones del franciscano, blanco de la furia del explorador francés, si no fuera por la aplastante unanimidad que existe sobre este punto.

La misión de la columna en el Isoso era la de encontrar y reabrir en caso necesario las sendas abiertas por los predecesores de Thouar en la región, como Antonio Rojas, Miguel y Cristián Suárez Arana6; debía buscar el camino hasta las salinas de Chiquitos dominadas por el cerro San Miguel, y de ahí abrir una ruta hasta Puerto Pacheco.

Desde las orillas del Parapetí, Thouar divisó un cerro que identificó como el San Miguel, pero que resultó ser el Curundaití «que tomó con ligereza por el San Miguel, sin más fundamento que el de presentar algún parecido con un diseño del verdadero San Miguel, que le había remitido don Cristián Suárez Arana, siendo tal error la causa eficiente del fracaso de la expedición» (Comisión, 1888: 3; Giannecchini, 1896: 48). De hecho, viendo el San Miguel donde no estaba, Thouar afirmó que la senda anteriormente abierta por Suárez Arana llevaba una dirección equivocada y no intentó alcanzarla (Comisión, 1888: 5). Más aún, y pese a que su identificación del San Miguel prometía una llegada relativamente fácil y rápida a las salinas, «lo extraño, lo soberanamente incomprensible» fue que, en vez de partir en esta dirección, Thouar decidió explorar los bañados del río Parapetí. Este «reconocimiento de interés geográfico sin duda, [...] no entraba en el campo de exploración que se le había señalado» (Comisión, 1888: 5).

La identificación errónea de otro cerro, el Curupautu, que Thouar creyó «ser el llamado Yoibide por el padre Lozano» (Comisión, 1888: 4)7 , no contribuyó a poner a los exploradores en el buen camino. Thouar despachó una comisión a Chiquitos (pasando por Santa Cruz), con el encargo de «establecer la autenticidad del cerro San Miguel» (Thouar, 1888: 3). Cuando, a su regreso, la comisión no pudo sino confirmar que el francés erraba en sus aseveraciones, Thouar no se inmutó y concluyó que «dos son los cerros que llevan el mismo nombre de San Miguel» (Thouar, 1888: 5); al mismo tiempo empezó a desarrollar una «idea muy rara», a saber que el Chaco boreal tenía en realidad un grado menos en longitud que lo establecido en el mapa elaborado por John Minchin en 1879, y considerado como el más confiable de la región'8. Ni esta conclusión ni los errores de identificación de los cerros aparecen en los libros que Thouar publicó posteriormente en los cuales, para beneficio de sus lectores franceses, el imperturbable explorador sigue trepando el «San Miguel»-Curundaití.

6 Sobre estas exploraciones previas, remito a Suárez Arana (2007 [1916]).

7 El cerro Yoibide está ubicado en todos los mapas jesuíticos del siglo XVIII, incluido el de Lozano, en el interior del Chaco, próximo a la misión de San Ignacio de Zamucos.

8 Carta de Thouar al ministro de Relaciones Exteriores, Macharetí, 3.VI.1887 (Ministerio de Relaciones Exteriores y Colonización, 1887: 8); Comisión, 1888: 19-20; Giannecchini, 1896: 140. 
La segunda parte de la expedición a orillas del Pilcomayo roza lo surrealista en partes. Desde Macharetí hasta Puerto Pacheco, el rumbo que debe tomarse es el noreste. Pero Arthur Thouar decide irse hasta la Colonia Crévaux, es decir hacia el sureste, en un «tortuoso e inesperado derrotero»: «la comisión informante ve un enigma indescifrable en la ruta sureste adoptada por Mr. Thouar» (Comisión, 1888: 21, 25). Al salir de Crévaux toma rumbo al norte, incluso noroeste, de tal manera que de marcha en contramarcha, «según informe de los expedicionarios a quienes ha oído la comisión, los indios decían que el camino que se seguía iba al Izozog〉 (Comisión, 1888: 27; Giannecchini, 1896: 200). Pocos días después, en Cumbarurenda, zona tapiete no tan alejada de la Colonia Crévaux, el infatigable francés descubre pozos y canales hechos a mano y que «[le] parecen por encima de la inteligencia de los indios»: debieron ser obra de los jesuitas de San Ignacio de Zamucos (Thouar, 1997 [1891]: 421; Giannecchini, 1896: 229) (no obstante haber identificado el cerro Yoibide de los zamucos en el Isoso).

Estas equivocaciones bien podrían haber sido corregidas por los baqueanos indígenas pero, según Giannecchini, Mr. Thouar no confía en ellos y por ende no sigue sus consejos (Giannecchini, 1896: 138, 145, 147, 175, 186). Al cabo de tantas órdenes y contraórdenes, a nadie le extraña cuando, el 10 de agosto, Thouar se separa del grueso de la tropa. «Nos abandonó», escribe Giannecchini (1896: 255).

Está claro que el padre Doroteo no es precisamente imparcial en el relato que hace de la malograda exploración Thouar. Despojándose de toda caridad cristiana, el exasperado franciscano se defiende de las acusaciones que pesan en su contra y no resiste al gusto de dejar mal parado a su contrincante. Su libro lleva la forma de un «diario» supuestamente escrito día tras día, pero evidentemente arreglado antes de su publicación. De esta manera, cuando el misterioso francés de la frontera avisa a Thouar (y este a Giannecchini) que debe desconfiar de los padres que mataron a Crévaux, el franciscano escribe:

mucho he dudado y aun dudo si la mencionada carta haya sido real o imaginaria del Sr. Thouar para tener un pretexto anticipado y preparado intencionalmente en el caso de un fracaso, para hacer recaer la responsabilidad de sus actos expedicionarios sobre un pobre fraile (Giannecchini, 1896: 137).

Esta frase fue claramente agregada una vez conocido el desenlace de la expedición. Pero, y sin absolver de toda culpa a Giannecchini, son demasiadas las voces que se alzaron acusando a Thouar como para pretender ignorarlas. Tras su partida el 10 de agosto, los expedicionarios eligen a Nicolás Ortiz, el médico de la tropa, como «jefe accidental» y firman todos un acta que reza:

En atención a la conducta observada por el Sr. Arturo Thouar, que abandonó su puesto, defraudando la aspiración de los expedicionarios, desertando de su seno con premeditación, sin consultar a la voluntad de los que le siguieron ni de los que quedaron en el campamento; separando, para conseguir su fin, a un grupo que hizo marchar a la Colonia Crévaux en comisión: acuerdan formular una protesta, que manifieste ante el supremo 
gobierno y el país, la indignación con que ha recibido la expedición este acto (Giannecchini, 1896: 274).

El mismo día, Nicolás Ortiz escribe al gobierno acerca de «la partida secreta del Sr. Thouar», poniendo en duda «la moralidad de sus actos»; aludiendo «al jefe que abandonó su puesto, se alejó de la bandera común, tal vez en pos de más brillantes lauros que, egoísta, quiere recoger solo» ${ }^{9}$.

Del lado de los predecesores de Thouar en el Chaco, las reacciones son las mismas. Cristián Suárez Arana evoca la «grave equivocación geográfica» de un Thouar «desorientado completamente en sus cálculos» sobre el cerro San Miguel, y agrega que «pretender tomar el Macharetí, cerca del Pilcomayo, como punto de partida para abrir la ruta que debía hacerse a Puerto Pacheco, era un absurdo lamentable» (Suárez Arana, 2007 [1916]: 71, 73). John Minchin, autor del mapa increpado por Thouar, publica en un periódico de Sucre una carta dirigida al francés donde le reprocha en duros términos su imperdonable «equivocación geográfica» (La Industria n. ${ }^{\circ}$ 795, 17.XII.1887: 3). Olaf Storm, quien ya hablaba en 1885 de los «errores astronómicos tan elementales» de Thouar, pone luego en tela de juicio la capacidad del explorador francés10.

A esta ya espantosa unanimidad se suma, como vimos, la comisión formada en Sucre a finales de 1887 para evaluar los resultados de la expedición (y que se formó, precisamente, por la falta de dichos resultados). Los integrantes de la comisión tachan de «elucubraciones» a los informes de Thouar; lo acusan de haber querido «alejar cuando le fuera posible el derrotero de la expedición del camino Suárez Arana» a las salinas, de ahí la «pintura intencionada de las dificultades y obstáculos que tendría que vencer la expedición» entrando al este del Isoso, para justificar su decisión de partir hacia Macharetí y el Pilcomayo... sin esperar a la comisión enviada a Chiquitos: «huyó pues Mr. Thouar ante la verdad». Concluye la comisión:

Puede creerse que abrumado el jefe por la absoluta desorientación en que había caído, concibió el pensamiento de imputar a unos u otros sus desvaríos (Comisión, 1888: 2, 6, 16-17, 26).

\section{UNA TOBA PARA DOS FRANCESES}

En este lamentable contexto debe leerse la historia de Yalla tal como fue contada por Thouar. Al igual que Giannecchini, Thouar utiliza un supuesto «diario», escrito «sobre la marcha» pero cuidadosamente arreglado antes de su publicación para, en este preciso caso, justificar lo injustificable de su fracaso. Saliendo de Lagunillas, es decir antes siquiera de penetrar en el Chaco, escribe por ejemplo: «no auguro éxito a esta exploración a través de esta zona [el Isoso] por muchas razones que

9 Carta de Nicolás Ortiz al ministro de Relaciones Exteriores, Crévaux, 28.VIII.1887 (Ministerio de Relaciones Exteriores y Colonización, 1887: 23-24).

10 Artículo publicado por Storm en Buenos Aires, junio de 1885, en Campos, 1888: 702; Storm, 1892. 
me dicta la experiencia, veo que está privada de agua» (Thouar, 1997 [1891]: 339-340): es, pues, uno de los pretextos que dará más tarde para explicar su fracaso en el Parapetí. Antes de relatar su primer encuentro con Yalla y observar la turbación creciente de un culpable Giannecchini, tiene también el cuidado de sugerir la verdadera naturaleza del fraile, que habría exigido que un desertor recibiera azotes mientras Thouar prefería conmutar una pena demasiado cruel. Es que así es la costumbre en las misiones franciscanas, «mientras el padre impasible preside esta escena salvaje contando los latigazos» (Thouar, 1997 [1891]: 367).

$\mathrm{Al}$ igual que Giannecchini contra las acusaciones de asesinato, Thouar se defiende contra aquellos que hablan de su ineptitud, pero se defiende atacando. El fracaso en el Isoso está primero imputado a la falta de agua; luego deriva de la mala voluntad demostrada por los colonos criollos de la región, cruceños opuestos al gobierno sucrense (Thouar, 1997 [1891]: 342, 346, 348); Suárez Arana se equivocó de senda y Minchin de un grado de longitud, aunque la explicación finalmente dada al gobierno boliviano sería que un camino por el Isoso favorecería demasiado a Santa Cruz en detrimento de Sucre11. Pero más allá de cruceños recalcitrantes y exploradores desubicados, no cabe duda de que los culpables predilectos de Monsieur Thouar son los indios del Pilcomayo, y los misioneros franciscanos.

El mismo explorador que no dudaba en afirmar en 1883 (a pesar del recuerdo todavía fresco de la masacre de la misión Crévaux) que «los indios no son un obstáculo serio al desarrollo de la colonización12》) aparece en 1887 rodeado, al menos en el papel, de indígenas hostiles y sanguinarios. En palabras de Giannecchini:

Mr. Thouar quería a todo trance para justificar su fracaso que los indios estuvieran de a malas (Giannecchini, 1896: 327).

Pero Thouar no acusa a «los indios» en general, sino más específicamente a los tobas: una fogata que alumbra la noche «es sin duda una señal afanosa de los tobas indicando nuestra presencia en el Pilcomayo»; «me persigue la preocupación de cómo vamos a arreglarnos para partir con los tobas» (Thouar, 1997 [1891]: 400, 402). «Troncos, palos, ruido de las hojas movidas por el viento, todo es toba; y tobas, ique nos vienen a espiar, a comer!»(Giannecchini, 1896: 159). Por un lado, es un hecho que los tobas tienen la fama de ser los indígenas más feroces del Pilcomayo, «sempiternos enemigos de todo elemento de civilización» (Jofré, 2006 [1895]: 505). Por otro lado, y más importante, son los asesinos de Crévaux; entre aquellos que acechan la expedición Thouar y quieren masacrarla sin piedad figura Cototo, uno de los asesinos denunciados por Yalla.

Esta es la razón por la cual las acusaciones contra los tobas vienen acompañadas de otras contra los padres franciscanos, culpados en 1882 del asesinato de Crévaux. Esta es, sobre todo, la razón de la presencia de Yalla, la «joven inteligente» de 1882 que acaba de consolidar esta siniestra relación entre tobas asesinos, misioneros italianos y la muerte de Crévaux.

\footnotetext{
11 Carta de Thouar al gobierno boliviano, citada en Comisión, 1888: 17.

12 Carta de Thouar, 17.XI.1883, en Campos, 1888: 697.
} 
Como se habrá percatado el lector, en el relato de Thouar cada una de las apariciones de Yalla coincide con acusaciones cada vez menos veladas contra los franciscanos en general y Giannecchini en particular. Y cada una de estas acusaciones se refiere a la trágica expedición Crévaux de 1882. En Teyu donde Thouar se entrevista el 7 de julio con Yalla, Giannecchini encuentra a un indígena toba y lo abraza: «me parece ver en esta misma playa, donde cinco años atrás fueran cobardemente masacrados Crévaux y sus compañeros, surgir el cadáver de nuestro compatriota entre el misionero y el toba» (Thouar, 1997 [1891]: 404); cuando, después de este escena, los colonos de Caiza empiezan a desconfiar de Giannecchini, también reprochan a Thouar de «ser tan ciego como Crévaux que no quiso escuchar a nadie» (Thouar, 1997 [1891]: 405); cuando los tobas se preparan a atacar más tarde en agosto, los neófitos de las misiones franciscanas llegan a alentarlos; cuando el coronel Martínez quiere salir en pos de Thouar a finales de septiembre, es otro franciscano, el P. Sebastián Pifferi, quien supuestamente intenta disuadirlo por todos los medios (Thouar, 1997 [1891]: 467).

Las amenazas que los tobas y sus cómplices franciscanos hacen pesar sobre Thouar en 1887 no solo sirven como una justificación más de su fracaso: son también, o sobre todo, una reedición de la historia de Crévaux. Es pues un hecho que, si comparamos los relatos de Thouar acerca de sus diversas expediciones, el francés aparece mucho más preocupado por la suerte de su paisano en 1887 que en 1883, cuando el objetivo de su viaje era investigar sobre su muerte. Como lo notó Vaultier (2005), durante toda su carrera profesional, Thouar quiso situarse como el sucesor de Crévaux. Ya en 1884 terminaba el relato de su expedición escribiendo:

Perteneciendo a una Sociedad [la Sociedad Geográfica de Francia] altamente honorable en América del Sur, ¿no debía yo afirmarme entonces, relevando a nuestro caído compatriota? [...] y ese pequeño trozo de tela, lacerado, manchado en la mano crispada de Crévaux, ya frío de muerte, estrechando los jirones en un último espasmo, en una suprema contracción, ¿quién pues debía ir a buscar todo aquello? ¿No tenía entonces que ser un francés? (Thouar, 1997 [1891]: 163).

Poco después, a punto de internarse en el delta del Pilcomayo, escribe que «la obra del Dr. Crévaux va a recibir por fin una primera sanción»13. Al iniciar la exploración de 1887, también recuerda al médico francés: «Partió. iSabemos qué pasó! Más afortunado que él, yo pude realizar su plan en 1883» (Thouar, 1997 [1891]: 317). Thouar ganó pues en 1884 la medalla de oro de la Sociedad Geográfica de París precisamente por haber ido en busca de Crévaux (Roux, 1997: 32), y su relato (junto con las ilustraciones de Riou basadas en su texto) tiene no poca responsabilidad en la invención del «mito Crévaux» y el de sus salvajes asesinos (Chaumeil, 2009). Para asentar este papel de sucesor, ¿qué mejor que hacerse casi (solo casi) masacrar por los mismos indios y la complicidad del mismo misionero? En este punto también interviene, pues, Yalla, cuya presencia relaciona de forma obligada las amenazas indias, los franciscanos, la trágica muerte de Crévaux y el destino de Thouar.

13 Carta de Thouar a un amigo, junio de 1885, citada por Vaultier, 2005. 
Que Yalla haya existido de verdad es algo fuera de duda. Sirvienta en Tarija, partió como embajadora en 1882 y no volvió. Son los únicos datos históricos comprobados que conocemos sobre ella. Como ya mencioné, la primera entrevista de Yalla con Thouar en mayo de 1887 en San Francisco tuvo probablemente lugar en el sitio y la fecha indicados. La seguridad no es la misma en cuanto a los encuentros posteriores a orillas del Pilcomayo, en el secreto de la noche y sin testigos. Lo más probable es que estas entrevistas solo existieron en la imaginación de Thouar, en consonancia con el personaje construido e inventado de «la valiente toba» salvadora. La trama de la historia contada por Thouar es pues difícil de creer. Cuando Yalla denuncia como futuros asesinos de Thouar a aquellos tobas que estuvieron presentes en Macharetí, estaría pues acusando a su propio padre Caligagae que participó de la entrevista celebrada; tampoco es muy creíble que, en agosto y septiembre, cientos de indígenas hayan esperado pacientemente día tras día para asesinar (siempre «más abajo» y siempre «más tarde») a un puñado de exploradores agotados y muertos de sed en el desierto —ni se entiende cómo pudieron conseguir agua estos cientos de indios ahí donde los exploradores no conseguían ni una gota-. Francamente imposible es el hecho de que Yalla haya podido estar en la Colonia Crévaux pidiendo a un choroti guiar al coronel Martínez y, al mismo tiempo, prestarse a otra entrevista nocturna con Thouar varios días de camino más allá.

La duda no está permitida. La Yalla que, como sombra protectora, recorre todo el libro de Thouar, fue introducida por él para dar cuerpo y realidad a amenazas que, sin ella, no tendrían consistencia ni asidero. Parte de esta construcción fue el arreglo, en el libro de 1891, del texto publicado en 1884. Thouar no cambia ni una coma a su vehemente defensa de los franciscanos, insiste incluso en 1891 en que «defendía siempre» a Giannecchini (Thouar, 1997 [1891]: 405), por lo cual sus posteriores acusaciones no pueden ser atribuidas a un prejuicio anterior. Pero sí agrega los párrafos que delatan sin ambigüedad la traición de Yalla. Gracias a estas líneas, la toba de 1882 aparece como comprobada traidora sin que la duda esté permitida. Thouar es en realidad el único que acusa formalmente de esta manera a Yalla: los demás solo constatan que no vuelve, o incluso hablan de su papel de salvadora de Haurat. Pero una Yalla culpable en 1882 es mucho más creíble en 1887 y sus revelaciones sobre la muerte de Crévaux no pueden ponerse en duda —ni, por tanto, su denuncia de un complot contra Thouar- La Yalla de 1887 tiene, en definitiva, tan poca consistencia histórica como la Yala de papel inventada por Novis en su cuento. La mejor prueba tal vez sea el informe final que Thouar entregó en enero de 1888 al gobierno boliviano, en el cual no dice palabra de las amenazas de los feroces tobas ni mucho menos evoca a Yalla o al complot franciscano en su contra.

\section{PALABRAS FINALES}

Las acusaciones que se disparan contra Thouar al finalizar la expedición de 1887 no son las primeras que se emiten en su contra. Otros le reprocharon la misma 
obstinación en no seguir a los baqueanos indígenas y la misma intención de separarse del grueso de la tropa en una «marcha traicionera» en la expedición de 188314. Tras esta misma expedición, y a pesar de su éxito, Thouar acusó a Daniel Campos de haberla saboteado e incluso de haber querido hacerlo asesinar; también se atribuyó todo el mérito de la expedición, en realidad dirigida por Campos. En esta ocasión las acusaciones no desembocaron en nada concreto, y Thouar tuvo que retractarse (Dory, 2005)15. En otro orden de mitificaciones, Campos también publicó un artículo donde, si bien elogió la valentía del francés en una pelea en octubre de 1883 contra los indígenas, negó «la existencia de otros combates descritos con mucha jactancia por Thouar» (Roux, 1997: 34)16.

La mentira toba de 1887 tal vez tuvo mejor suerte en Francia, donde los lectores carecían de elementos para detectarla. Formó, además, parte integrante de las aventuras chaqueñas de Thouar tal como las cuentan las publicaciones de Le Tour du Monde y el libro de 1891: una novela repleta de héroes y villanos, indios salvajes, medioambiente hostil, fieras, combates, sufrimientos felizmente superados, donde hasta las ilustraciones de Riou (dibujante, entre otros, de varias de las novelas más famosas de Julio Verne) contribuyeron a darle un sabor de Viaje Extraordinario y crear un clima de irrealidad donde la ficción —o la mentira- no se distingue de la realidad.

Thouar no es, de lejos, el único autor de relatos de viaje que se permitió acomodar datos o magnificar sus hazañas, ya sea para el gusto de sus lectores, acrecentar su fama o situarse en el linaje de gloriosos ancestros. Textos, dibujos y fotografías circulaban, se copiaban, se plagiaban y se reeditaban, no siempre de buena fe (cf. Chaumeil, 2009); la literatura «sentimental» de viaje (Pratt, 2010), poniendo en primer plano las vivencias y los sentimientos del autor, se constituyó tempranamente en un terreno predilecto para esta clase de manipulaciones. Pero, si bien ningún documento es inocente, algunos lo son menos que otros. La magia de la novela no tuvo larga vida. Aunque no se percatan de la manipulación de la figura de Yalla, los historiadores y geógrafos que se interesaron por Thouar apuntan todos sin excepción lo polémico del personaje, sus acusaciones a diestra y siniestra, sus mentiras y sus garrafales errores geográficos (Roux, 1997; Dory, 2005; Vaultier, 2005). La carrera de Thouar como geógrafo amateur y explorador tampoco parece haber sobrevivido por mucho a su fracasada expedición chaqueña. En los años siguientes aparece dando algunas conferencias en Francia, pero no dirige ninguna otra exploración, no vuelve más a Bolivia, y su rastro se esfuma a inicios del siglo XX. No se sabe ni dónde ni cuándo murió (Dory, 2005; Vaultier, 2005).

Del lado boliviano, la aparición nocturna de Yalla en vísperas del rescate de Thouar es la última mención que encontré de ella. No vuelve a aparecer, ni siquiera

14 Carta de David Gareca a Antonio Quijarro, Caiza, 2. XII.1885, en Campos, 1888: 710-715.

15 Varias cartas sobre esta polémica en Campos, 1888: 575 y sig.

16 Sin embargo, al principiar la expedición de 1883, Campos no encontraba suficientes elogios para Thouar, «explorador de nota», «espíritu guerrero y emprendedor», al que le unía una «íntima y fraternal amistad» (Campos, 1888: 356, 365). 
para cobrar su justa recompensa. En 1891 su padre solicita la creación de una misión exclusiva para los tobas, que nunca se hará realidad (Anales, 2006 [18791905]: 1312). En cuanto al objetivo mismo de la expedición de 1887, no tardó en esfumarse: en septiembre de 1888, Puerto Pacheco caía en manos paraguayas. De una expedición desastrosa solo quedó la huella en el papel. Dos libros, cientos de páginas de informes furibundos y denuncias virulentas, unos cuantos croquis, unos cuentos: el de Novis, que pone en escena a una Yala mataca, tímida enamorada de un héroe francés que acaba olvidándola y casándose con otra; el de Thouar, donde el nombre de Yalla quedó estampado como el escudo de un orgullo herido.

\section{Agradecimientos}

Este artículo se escribió en el marco del proyecto $\mathrm{I}+\mathrm{D}+\mathrm{i}$ del MINECO/FEDER (Ref. HAR2015-64891-P) desarrollado por el TEIAA (2014SGR532), grupo de investigación consolidado por el Comissionat per a Universitats i Recerca del DIUE de la Generalitat de Catalunya. Agradezco al Instituto Francés de Estudios Andinos por apoyar mi investigación y a Pilar García Jordán y a Diego Villar por sus comentarios a este artículo.

\section{Referencias citadas}

ANALES, 2006 [1879-1905] - Anales de este Colegio Franciscano de Tarija desde el año 1879. In: Presencia franciscana y formación intercultural en el sudeste de Bolivia según documentos del archivo franciscano de Tarija 1606-1936, t. VI (L. Calzavarini, ed.): 1235-1484; Tarija: Centro Eclesial de Documentación.

BARNADAS, J. (dir.), 2002 - Diccionario histórico de Bolivia, 2 t.; Sucre: Grupo de estudios históricos.

CAMPOS, D., 1888 - De Tarija a la Asunción. Expedición boliviana de 1883, 785 pp.; Buenos Aires: Jacobo Peuser.

CHAUMEIL, J.-P., 2009 - Primeros clichés. Las tribulaciones del doctor Crévaux en la Amazonía. In: Entre textos e imágenes. Representaciones antropológicas de la América indígena (F. del Pino-Díaz, P. Riviale \& J. J. Villarías-Robles, eds.): 213-225; Madrid: CSIC.

COMISIÓN, 1888 - Informe de la comisión informadora sobre la expedición Thouar, 28 pp.; Sucre: Archivo de la Casa de la Libertad (Sucre) 3-1-14 no 886.

CORRADO, A., 1884 - Continuación de la historia del Colegio Franciscano de Tarija. In: El Colegio franciscano de Tarija y sus misiones. Noticias históricas recogidas por dos misioneros del mismo Colegio (A. Comajuncosa \& A. Corrado): 279-503; Quaracchi: Colegio de San Buenaventura.

DORY, D., 2005 - Arthur Thouar dans le Chaco bolivien (1883-1887). Objectifs, contextes et résultats. In: Hommes de science et intellectuels européens en Amérique latine (XIX-XXe siècles) (J. Farré, F. Martínez \& I. Olivares, eds.): 59-77; París: Le Manuscrit.

GARCíA JORDÁN, P., 2001 - Cruz y arado, fusiles y discursos. La construcción de los Orientes en Perú y Bolivia, 1820-1940, 476 pp.; Lima: IFEA, IEP. 
GIANNECCHINI, D., 1896 - Diario de la expedición exploradora boliviana al Alto Paraguay de 1886-1887, 359 pp.; Asís: Tip. de la Porciúncula.

GIANNECCHINI, D., 1988 [1879] - Apuntes originales de la historia de las misiones de 1874 a 1879. In: Historia de Tarija (Corpus documental), t. V (E. Langer \& Z. Bass Werner de Ruíz, eds.): 320-333; Tarija: Universidad Autonóma «Juan Miseal Saracho».

GIANNECCHINI, D., 2006 [1882] - Relación de lo obrado por los padres misioneros del colegio de Tarija en las dos expediciones fluvial y terrestre al Pilcomayo del año de 1882. In: Presencia franciscana y formación intercultural en el sudeste de Bolivia según documentos del archivo franciscano de Tarija 1606-1936, t. V (L. Calzavarini, ed.): 625-666; Tarija: Centro Eclesial de Documentación.

GROFF GREEVER, J., 1987 - José Ballivián y el oriente boliviano, 451 pp.; La Paz: Siglo.

JOFRÉ, O., 2006 [1895] - Colonias y misiones. Informes de la visita practicada por el delegado del Supremo Gobierno. In: Presencia franciscana y formación intercultural en el sudeste de Bolivia según documentos del archivo franciscano de Tarija 16061936, t. IV (L. Calzavarini, ed.): 453-533; Tarija: Centro Eclesial de Documentación.

LANGER, E., 2009 - Expecting Pears from an Elm Tree. Franciscan Missions on the Chiriguano Frontier in the Heart of South America, 1830-1949, 375 pp.; Durham: Duke Press University.

MINISTERIO DE RELACIONES EXTERIORES Y COLONIZACIÓN, 1887 - Boletín n. ${ }^{\circ}$ 7, oct. de 1887; Sucre.

NOVIS, T., c. 1890 - Captivité chez les Indiens Matacos et Tobas. Étude des mœurs et coutumes des Indiens du Chaco. Leur civilisation possible, 205 pp.; Sucre: Archivo y Biblioteca Nacionales de Bolivia MSS Libro 1.

PAZ GUILLÉN, J., 1886 - A través del Gran Chaco. Relación de viaje de la expedición militar boliviana en 1883, 80 pp.; Buenos Aires: Imprenta Jacobo.

PRATT, M. L., 2010 - Ojos Imperiales. Literatura de viajes y transculturación, 471 pp.; México: FCE.

ROUX. J.-C., 1997 - Thouar, el explorador del Chaco: las tribulaciones de un geógrafo improvisado en América del Sur. In: A través del Gran Chaco, 1883-1887 (A. Thouar): 13-37; La Paz-Cochabamba: Los Amigos del Libro.

SUÁREZ ARANA, C., 2007 [1916] - Apuntes históricos y geográficos. In: Exploraciones: 5380; Santa Cruz: Fundación Nova.

STORM, O., 1892 - El río Pilcomayo y el Chaco boreal, 151 pp.; Buenos Aires: Cia sudamericana de billetes de banco.

THOUAR, A., 1884 - À la recherche des restes de la mission Crévaux. Le Tour du Monde, XLVIII: 209-272.

THOUAR, A., 1888 - Informe de la expedición al Alto Paraguay, 30.I.1888, 6 pp.; Sucre: Archivo de la Casa de la Libertad, 3-1-6: no 906.

THOUAR, A., 1889 - Voyage dans le Chaco boréal. Le Tour du Monde, LVIII (2): 161-208; París.

THOUAR, A., 1890 - Voyage dans le Chaco boréal. Le Tour du Monde, LIX (1): 177-218; París.

THOUAR, A., 1891 - Explorations dans l'Amérique du Sud, 421 pp.; París: Hachette.

THOUAR, A., 1997 [1891] - A través del Gran Chaco, 1883-1887, 476 pp.; La PazCochabamba: Los Amigos del Libro. 
TRATADO, 1988 [1884] - Tratado de paz entre los blancos con los tobas, noctenes, tapietes y chorotis. In: Historia de Tarija (Corpus documental), t. V (E. Langer \& Z. Bass Werner de Ruíz, eds.): 252-254; Tarija: Universidad Autonóma «Juan Miseal Saracho».

VAULTIER, J.-B., 2005 - Arthur Thouar: le Grand Chaco, I'explorateur, I'aventurier et la Société de Géographie. In: Hommes de science et intellectuels européens en Amérique latine (XIX-XXe siècles) (J. Farré, F. Martínez \& I. Olivares, eds.): 37-58; París: Le Manuscrit. 
Pedidos: IFEA, Casilla 18-1217, Lima 18 - Perú, telf. 2436090

E-mail: Alina.Wong@cnrs.fr - Web: http://www.ifea.org.pe

\section{Fernanda Molina}

\section{Cuando amar era pecado}

Sexualidad, poder e identidad entre los sodomitas coloniales (Virreinato del Perú, siglos XVI-XVII)
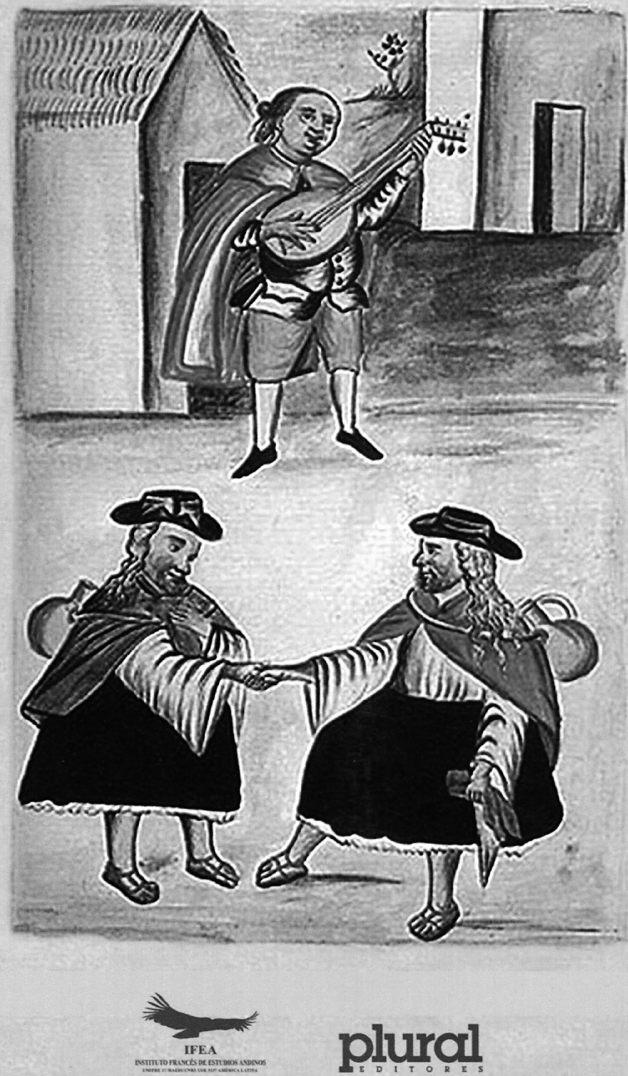